\title{
Diurnal changes in photosynthetic activity of the biological soil crust and lichen: Effects of abiotic factors (Petuniabukta, Svalbard)
}

\author{
Luděk Sehnal", Miloš Barták, Peter Váczi
}

Department of Plant Physiology and Anatomy, Institute of Experimental Biology, Faculty of Science, Masaryk University, Kamenice 5, 62500 Brno, Czech Republic

\begin{abstract}
In polar ecosystems, primary producers have to cope with a very harsh climate that limits the time available for growth and biomass production. In this study, diurnal measurement of photosynthetic processes in biological soil crust and a lichen were carried out in Petuniabukta, Spitsbergen. For field measurements, a method of induced fluorescence of chlorophyll was used. Measurements of photosynthetic activity were taken as repetitive measurements of effective quantum yield of photosystem II ( $\left.\Phi_{\text {PSII }}\right)$. The short-term field measurements were carried out for 10 days in summer 2014 . $\Phi_{\text {PSII }}$ was recorded each 5 minutes as well as microclimatic data (air temperature, air humidity, photosynthetically active radiation - PAR). The microclimatic parameters were recorded by a datalogger. In general, physiological activity of both biological soil crust and a lichen showed daily courses. Tested lichen was Cladonia rangiferina and the most dominant species in biological soil crust was Nostoc sp. Typically, most of $\Phi_{\text {PSII }}$ values ranged $0.6-0.7$ in both model organisms. The results have shown that photosynthetic activity was strongly correlated with all observed abiotic factors in both study objects. Particularly important was the relation found between PAR and $\Phi_{\mathrm{PSII}}$ in biological soil crust. When the biological soil crust was exposed to high PAR doses of irradiation (about $2300 \mu \mathrm{mol} \mathrm{m} \mathrm{m}^{-2} \mathrm{~s}^{-1}$ ) photoinhibition of primary processes of photosynthesis was observed as $\Phi_{\mathrm{PSII}}$ decrease, while photosynthetic activity of lichen remained at same level. Furthermore, it has been demonstrated increasing that in situ photosynthetic activity increased in both biological soil crust and lichen with a decrease in temperature.
\end{abstract}

Key words: Spitsbergen, lichen, biological soil crusts, photosynthesis, fluorescence, effective quantum yield, Cladonia rangiferina, Nostoc sp.

Abbreviations: $\Phi_{\mathrm{PSII}}-$ quantum yield of photosystem II, BSCs - biological soil crusts, LSCs - lichen-dominated soil crusts, PAR - photosynthetically active radiation

DOI: $10.5817 / \mathrm{CPR} 2014-2-16$

Received October 30, 2014, accepted December 30, 2014.

*Corresponding author: Luděk Sehnal <350222@mail.muni.cz>

Acknowledgements: The authors thank CzechPolar project for infrastructure used during field campaign and laboratory work. 


\section{Introduction}

An organism that thrives in an extreme environment is an extremophile; in more than one extreme it is a polyextremophile. An organisms living in polar regions are exposed to various factors of harsh polar environment and they thrive there. It means that organisms living in polar habitat must be polyextremophilic. All polar species are strongly adapted to environmental stresses such as low temperature, different levels of irradiation or lack of water and their phenology is finely tuned to the strong seasonal changes of the environmental factors. Arctic species are less adapted to environmental stresses than Antarctic one due to shorter cold history (Wiencke et al. 2006).

Biological soil crusts (BSCs) and lichens are dominant in arid and semi-arid Earth regions. In spite of an increasing interest in structure and function of BSCs in last decades, number of papers dealing with BSCs physiology, photosynthetic processes in particular, is still low. In some Earth regions, BSCs have a very wide distribution and provide $40 \%-100 \%$ of the ground cover in areas with relatively sparse vascular plant cover (St. Clair et al. 1993) such as hyperarid, arid, semiarid, subhumid, alpine and polar regions (Belnap 2006). It has been shown that microbiotic soil crusts are formed by an interaction between bacteria, small soil-dewelling animals, algae, fungi, moss and lichen (Danin 1978, Schulten 1985, Tsoar and Moller 1986, Eldridge 1993). The crusts are formed by the entanglement of cyanobacteria and algae filaments, lichen and moss thalli and soil particles (Chartres 1992). Moreover, cyanobacteria and microphytes produce gelatinous substances that causes adhere of clay particles and thus concentrate the microorganisms at soil surface (Li et al. 2002). The formation of BSCs begins with the colonization by filamentous cyanobacteria on the sand surface. Subsequently, the crusts gradually develop to the stages of lichen soil crusts (LSCs) (Wu et al. 2013) thank to an increased establishment of lichen thalli in soil crust. The importance of soil crust development in ecological functioning in arid and semi-arid regions is well established (e.g. West 1990, Yair 1990, Eldridge et Greene 1994, Harper et Marble 1988). They influence different aspects of the soil water regime, including soil porosity, absorptivity, roughness, aggregate stability, soil texture, pore formation and water retention (e.g. Campbell 1979, Yair 1990, Eldridge et Greene 1994, Harper et Marble 1988).

In polar regions, lichens dominate on rock surfaces or inside rocks and stones (endolithic communities) but are also found on the surface of moss turfs (Pannewitz et al. 2005). The absence of roots for water uptake and of epidermis and cuticula as a water-preserving protection characterizes lichens as poikilohydrous plants. Thus, their metabolic activity (e.g. photosynthetic and respiratory $\mathrm{CO}_{2}$ exchange) fully depends on the moisture conditions of the substratum and atmosphere. This simple anatomic structure and thallus morphology, combined with a high desiccation tolerance, allows an opportunistic life strategy. Lichens are usually subjected to dramatic changes of osmotic concentrations and volume. They also show extremely high dehydration and freezing tolerance, and maintenance of full photosynthetic capacity over a wide range of partial dehydration and thallus temperature. (Kappen 1993).In this study, attention is devoted to the comparison of lichen and BSCs photosynthetic activities in relation to environmental factors. To assess of physiologic activity of tested species, we used monitoring of daily changes in $\Phi_{\mathrm{PSII}}$. Physiology of photosynthesis in soil crust in Polar regions has been investigated to only limited extend. Only few in vitro studies focused physiology of different Klebsormidium sp. populations from Alpine soil 
crusts (Karsten et al. 2010, Karsten et Holzinger 2012, Kitzing et al. 2014). Comparative in situ studies focused on physiology lichens and BSCs are missing. Therefore, this work provides some pre- liminary data from in situ simultaneous measurements of primary photochemical processes of the two ecologically important representatives of Polar flora.

\section{Material and Methods}

\section{Research sites}

Study site is located in Petuniabukta (Spitsbergen, Billefjorden, $78^{\circ} 41^{\prime} \mathrm{N}, 16^{\circ} 26^{\prime} \mathrm{E}$ ). The site has midnight sun from the middle of April until the end of August. Study site is located $50 \mathrm{~m}$ E of Petunia station on the first terrace close to the coastal line $(200 \mathrm{~m})$. Vegetation cover of the site is dominated by lichens and biological soil crusts. The study site is supplied by water from melting snowfields in the early spring, but water limitation may occur during the second half of summer season (in August).

\section{Species taxonomy}

Determination of tested species was carried out during of the expedition on Svalbard. For determination was used light microscope and taxonomical key. This taxonomical overview of species on Svalbard was created by Jiří Komárek and Josef Elster. In biological soil crust, dominant cyanobacterial species were Nostoc sp., Microcoleus sp. and Gleocapsa sp. Algal dominant species in biological soil crust were Trebouxia sp. and Coccomyxa sp. Lichen, used for this experiment, was Cladonia rangiferina.

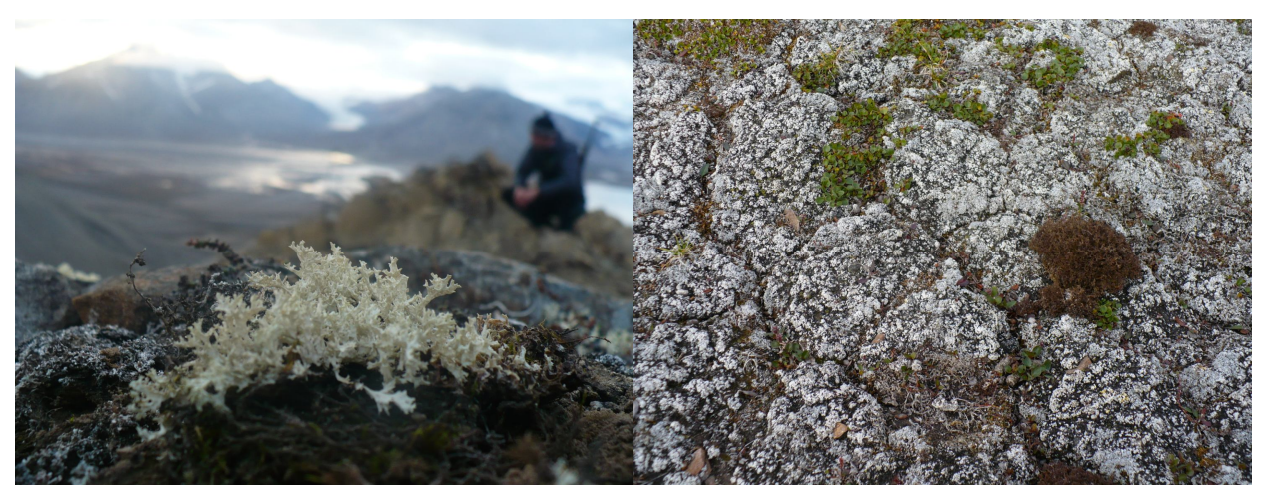

Fig. 1. Pictures of tested organisms. In the left picture is lichen Cladonia rangiferina and biological soil crust is showed in the picture to the right.

\section{Microclimate}

To determine changes of environmental conditions during the field experiment, basic microclimatic data were recorded. Temperature and relative air humidity were measured in each five minute by Minikin datalogger (EMS Brno, Czech Republic). Photosynthetically active radiation (PAR) was measured and recorded by Moni-PAM 2000 (Heinz Walz, Germany) at each chlorophyll fluorescence measurement event (every 5 min.). 


\section{Chlorophyll fluorescence measurement}

Short-term comparative measurements of photosynthetic activities in lichen and biological soil crust was carried out during the Czech expedition in Petunia Bukta in August 2014 . For measuring of diurnal course of $\Phi_{\mathrm{PSII}}$ we used multichannel monitoring fluorometer Moni-PAM 2000 (Heinz Walz, Germany; see Fig. 2.). The fluorometric system was installed in a close vicinity of Petunia station located at Petunia Bay from 5 to 15 August 2014. The measuring apparatus consisted of two fluorometric probes linked to a controlling and data storing unit (Moni-DA, Heinz Walz, Germany). The saturation pulse analysis of chlorophyll fluorescence were carried out each five minutes in the actual light-adapted physiological state of tested species. Within the measurement, saturation pulse was applied to determine steady-state fluorescence (Fs) and maximal fluorescence on light-adapted sample $\left(\mathrm{F}_{\mathrm{M}}{ }^{\prime}\right)$. The effective quantum yield was calculated according to equation:

$\Phi_{\mathrm{PSII}}=\left(\mathrm{F}_{\mathrm{M}^{\prime}}-\mathrm{F}_{\mathrm{S}}\right) / \mathrm{F}_{\mathrm{M}^{\prime}}$

Eqn. 1.

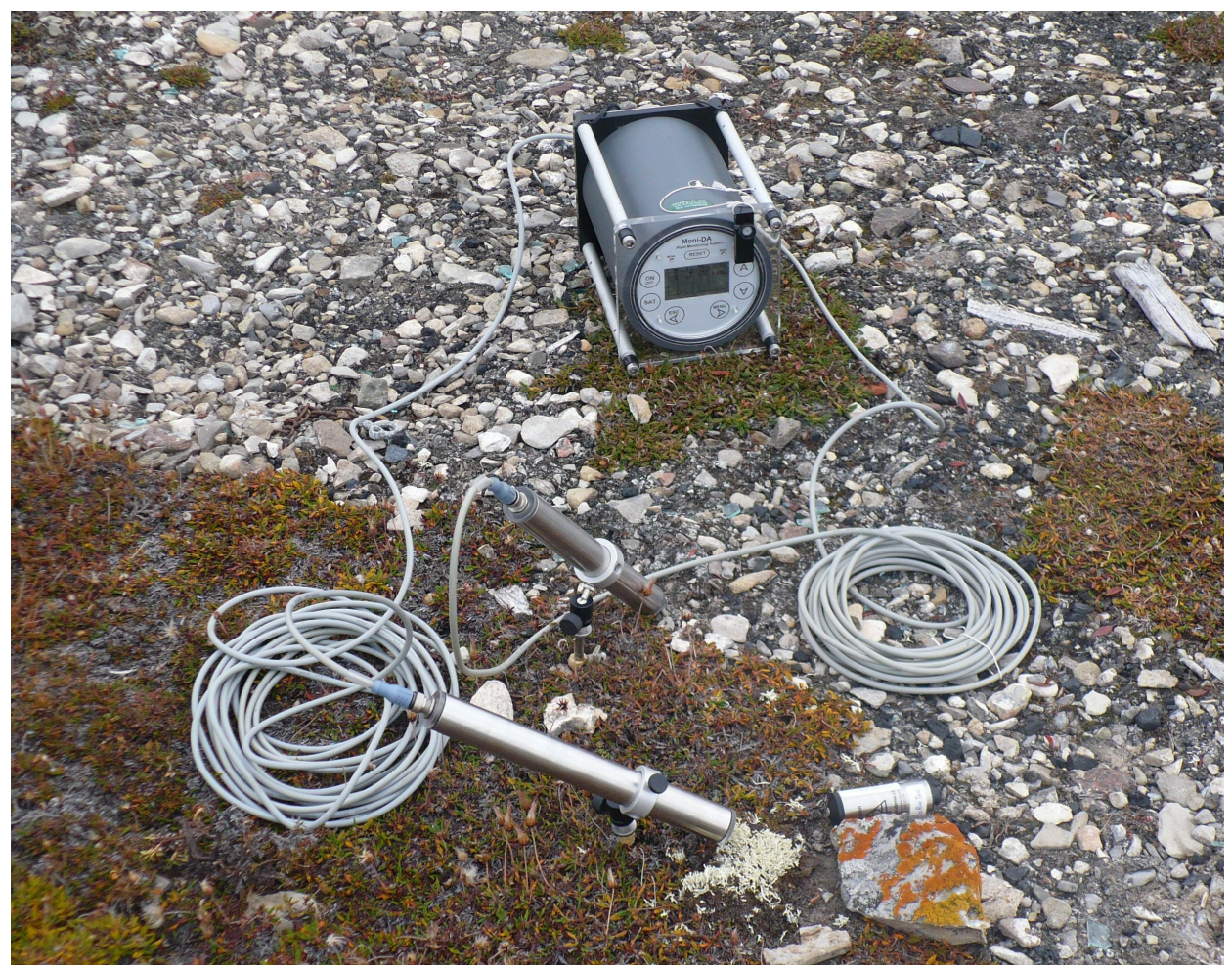

Fig. 2. Fluorometric system Moni-PAM (Walz, Germany). 


\section{Results}

\section{Microlimatic data}

Recorded microclimatic data shows relationship between temperature, air humidity and photosynthetically active radiation. Description of microclimate is necessary for evaluation of relations between primary processes of photosynthesis and abiotic factors. It's obvious that the relationship between temperature and radiation is directly proportional, while the relationship between both this factor and air humidity is inverse. The highest level of PAR was recorded in August $9\left(2258 \mu \mathrm{mol} \mathrm{m}^{-2} \mathrm{~s}^{-1}\right)$ and in the same moment, air humidity reach $24.8 \%$. The highest value of temperature was recorded in August $11\left(25.6^{\circ} \mathrm{C}\right)$ and air humidity was $21.05 \%$, which was the minimum recorded during the experiment. Average temperature for ten days measurement was $9.7^{\circ} \mathrm{C}$. Average humidity during the experiment was $72.2 \%$ and average photosynthetically active radiation was $600 \mu \mathrm{mol} \mathrm{m} \mathrm{m}^{-2}$.
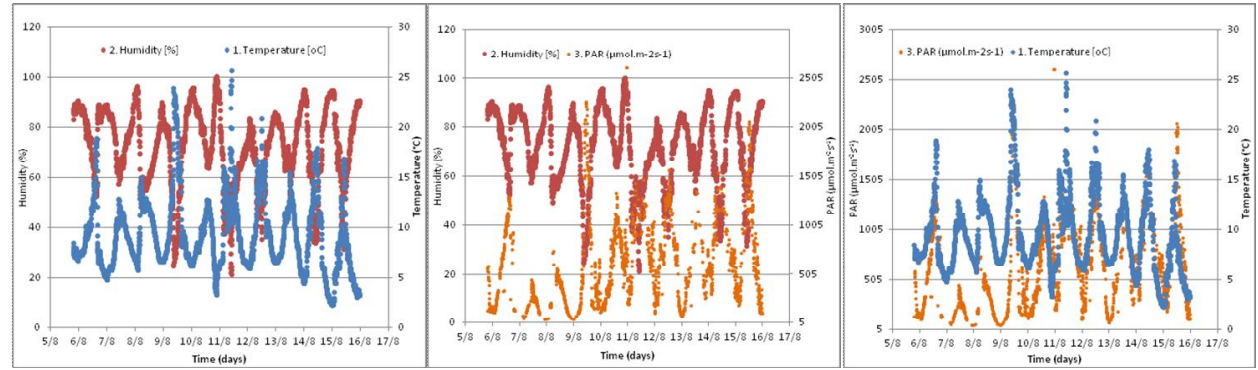

Fig. 3. Relationships between temperature, humidity and photosynthetically active radiation (PAR) in the field study.

\section{Photosynthetic activity - effective quantum yield}

In situ, environmental factors influenced physiology of exposed organisms together. However, for better understanding of driving factor was responsible for particular physiological effect, the data were analyzed for each factor separately.

Correlation of effective quantum yield of photosystem II and temperature in BSC and lichen is illustrated in Fig. 4. In the period of August 7 to 10, a gradual increase of temperature and a decrease of $\Phi_{\mathrm{PSII}}$ was observed in BSC. In a lichen, however, $\Phi_{\mathrm{PSII}}$ showed only a slight increase. In this particular period, most of $\Phi_{\mathrm{PSII}}$ values were found between $0.5-0.65$ in lichen and varied within the range of $0.6-0.7$ in biological soil crust. This was followed by a significant decrease of temperature on August $10^{\mathrm{th}}$ and rise again 11 August. From 12 August to the end of experiment, gradual decrease of temperature and increase of effective $\Phi_{\text {PSII }}$ was observed in both organisms. In this period, most of $\Phi_{\text {PSII }}$ values were found between $0.6-0.7$ in a lichen and $0.5-0.7$ in biological soil crust.

Relation between effective quantum yield and photosynthetically active radiation is shown in Fig. 5. The response of two organisms to the highest dose of radiation differed, as shown e.g. for August, $9^{\text {th }}$. Whereas effective $\Phi_{\mathrm{PSII}}$ of biological soil crust dramatically decreased, it increased in a lichen dramatically. Maximum values of PAR usually varied between $1400-1500 \mu \mathrm{mol} \mathrm{m} \mathrm{m}^{-2}$. High dose of PAR negatively influenced the biological soil crust, in which decrease of photosynthetic activity was observed $\left(\Phi_{\mathrm{PSII}}\right.$ drop). Under lower PAR dose $\Phi_{\text {PSII }}$ ranged 0.6 to 0.65 . 

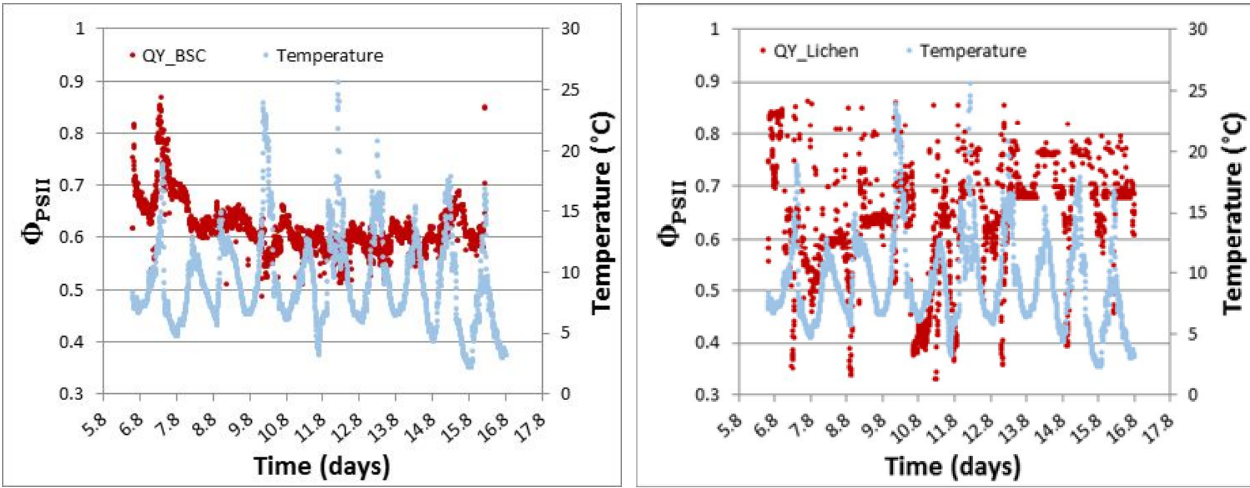

Fig. 4. Relation between effective quantum yield of photosystem II $\left(\Phi_{\mathrm{PSII}}\right)$ and temperature $\left({ }^{\circ} \mathrm{C}\right)$ in Cladonia rangiferina (right) and biological soil crust (left) during field experiment.
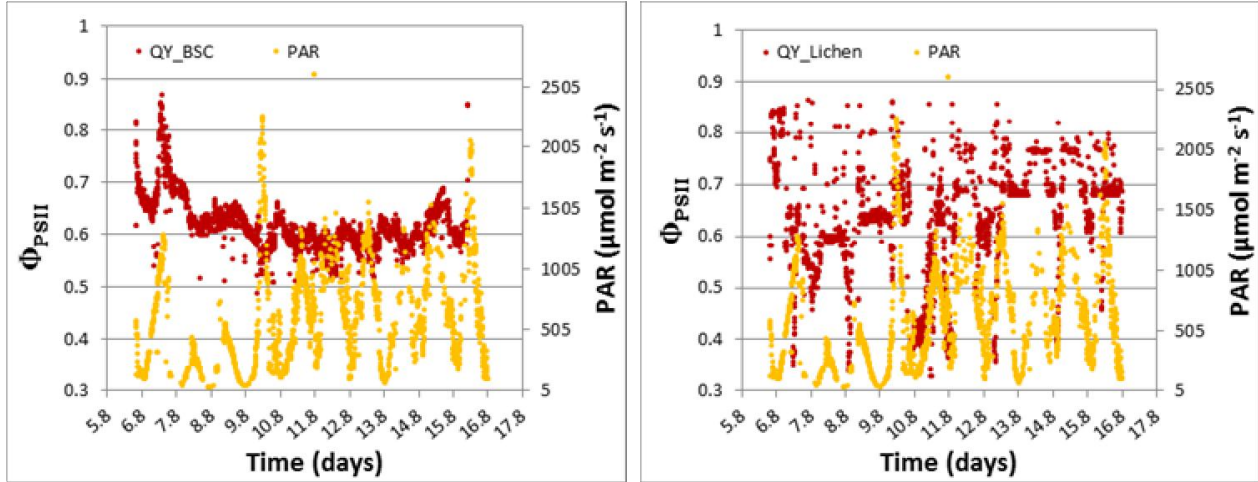

Fig. 5. Relation between effective quantum yield of photosystem II ( $\left.\Phi_{\text {PSII }}\right)$ and photosynthetically active radiation (PAR, $\mu \mathrm{mol} \mathrm{m}^{-2} \mathrm{~s}^{-1}$ ) in Cladonia rangiferina (right) and biological soil crust (left) during field experiment.
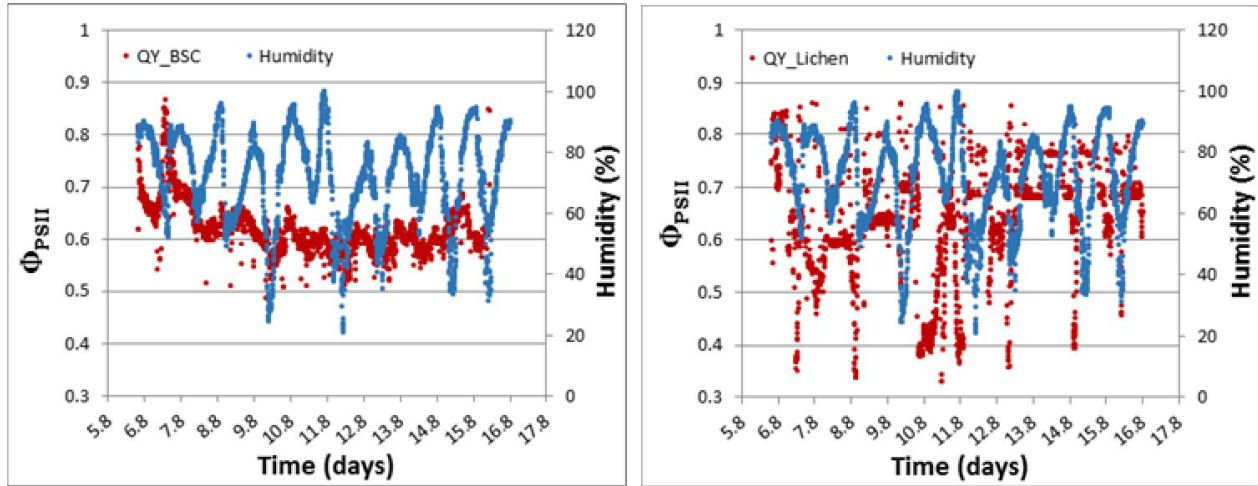

Fig. 6. Relation between effective quantum yield of photosystem II $\left(\Phi_{\mathrm{PSII}}\right)$ and humidity (\%) in Cladonia rangiferina (right) and biological soil crust (left) during field experiment. 
Relationship between relative air humidity $(\mathrm{RH})$ and photosynthetic activity $\left(\Phi_{\mathrm{PSII}}\right)$ is shown in Fig. 6. As mentioned above, RH courses were inversely proportional to temperature and PAR courses. During the highest doses of temperature (and PAR), RH values were found slightly above $20 \%$. Humidity maximum was recorded on August, $10^{\text {th }}$, when air temperature decreased dramatically. The peak of humidity was almost $100 \%$. Low RH was also observed during a decrease of effective $\Phi_{\text {PSII }}$ on August $9^{\text {th }}$ in biological soil crust. Similar effect was observed in lichen on August $15^{\text {th }}$, when temperature and PAR were about $18^{\circ} \mathrm{C}$, and $2000 \mu \mathrm{mol} \mathrm{m} \mathrm{m}^{-2} \mathrm{~s}^{-1}$ respectively. Under such conditions, RH was slightly under $40 \%$ and quantum yield of photosystem II reached about 0.45 .

Average $\Phi_{\text {PSII }}$ during the whole monitoring period was 0.62 in biological soil crust, respectively 0.63 in lichen. However, it is clear, that physiologic response to environmental factors was much more variable in lichen in comparison with biological soil crust.

\section{Discussion}

In biological soil crust and lichen, a good relation between physiological activity $\left(\Phi_{\mathrm{PSII}}\right)$ and physical factors was found. It is well comparable to the evidence from a wide variety of organisms (mainly lichens) investigated by a chlorophyll fluorescence approach, see e.g. Kappen et al. 1995, Kappen et al. 1996, Barták et al. 2005, Barták et al. 2007, Hájek et al. 2012.

However, differences in $\Phi_{\text {PSII }}$ courses were found between the studied organisms. Whereas the diurnal courses of $\Phi_{\text {PSII }}$ were more or less within the same range in biological soil crust, they varied in a lichen. This phenomenon might be attributed to contrasting morphology of the tested organisms. While biological soil crust forms a mats on soil surface, fruticose lichen thallus is branched above soil surface and thus much more exposed to variations physical environmental factors. This might be well documented for air temperature effects on $\Phi_{\text {PSII }}$ found in the period of August $7^{\text {th }}$ to $10^{\text {th }}$.

An temperature increase caused a $\Phi_{\text {PSII }}$ decreas in BSC. In contrast, $\Phi_{\text {PSII }}$ of lichen slightly increased in the same time. As expected, there was also a slow decrease of $\mathrm{RH}$ recorded in this period and thus decreased hydration of BSC resulting in a decline of photosynthetic activity. How- ever, mild increase of lichen physiologic activity in this period suggested that lichen can perform primary photosynthetic processes even under such low water availability. High resistance of lichens from polar regions to partial dehydration of thalli and maintenance of photosynthetic processes is well known and reported (e.g. Kappen 1993, Kappen et al. 1995, Henri 2011, Jupa et al. 2012, Wu et al. 2012, Barták 2014). An interesting effects was observed on August $9^{\text {th }}-10^{\text {th }}$, when a dramatic decrease of $\Phi_{\text {PSII }}$ was found and related to a decrease in air temperature. In BSC, contrastingly, $\Phi_{\text {PSII }}$ values grew up in the same time. The difference may be attributed to air temperature effects, since photosynthetic processes are temperature dependent (Lukeš et al. 2014). Moreover, phenomenon of moderate temperature photoinhibition was found in laboratory study (Barták et al. 2003).

On August $9^{\text {th }}, \Phi_{\text {PSII }}$ of a lichen was high while it decreased in BSC suggesting that BSC was moderately photoinhibited. This acute inhibition of primary processes in BSC could be attributed to high PAR values and low availability of water. However, interactions with other factors that may result in an increased sensitivity to photoinhibition may not be omitted since 
some of them may play a role even at low light (Allahverdiyeva et Aro 2012). In lichens from cold Earth regions, primary photochemical processes of photosynthesis in photosystem II (PS II) and thylakoid membrane of a chloroplast are effective at low above-zero temperature. This has been reported for lichens measured both in the field (Schlensog et Schroeter 2001) and a laboratory (Hájek et al. 2001). Our data support such conlusion. In the period of August, $12^{\text {th }}-15^{\text {th }} \Phi_{\text {PSII }}$ increased in both tested organisms in spite to decreasing temperature. In this particular case, a rise in $\mathrm{RH}$ caused an increase in $\Phi_{\mathrm{PSII}}$ even at decreasing temperature.

The main conclusions from the field measurements can be summarized as follows: (1) photosynthetic activity $\left(\Phi_{\mathrm{PSII}}\right)$ in lichen was much more variable than in biological soil crust, (2) both organisms exhibited a high level of photosynthetic activity under summer season microclimatic conditions, (3) primary processes of photosynthesis in PSII can be photoinhibited during the co-action of high PAR and several physical factors.

\section{References}

Allahverdiyeva, Y., Aro, E. (2012): Photosynthetic responses of plants to excess light: mechanisms and conditions for photoinhibition, excess energy dissipation and repair. Photosynthesis. 34: 275-297.

BARTÁK, M. (2014). Lichen Photosynthesis. Scaling from the Cellular to the Organism Level. In: Hohmann-Marriott, M. F. (ed.): The Structural Basis of Biological Energy Generation. Advances in Photosynthesis and Respiration Volume 39, pp. 379-400. ISBN 978-94-0178742-0.

BARTÁK, M., Gloser, J. and HÁJeK, J. (2005): Visualized photosynthetic characteristics of the lichen Xanthoria elegans related to daily courses of light, temperature and hydration: a field study from Galindez Island, maritime Antarctica. The Lichenologist, 37: 433-443.

BARTÁK, M., VÁCZI, P., HÁJEK, J. and SMYKLA, J. (2007): Low-temperature limitation of primary photosynthetic processes in Antarctic lichens Umbilicaria antarctica and Xanthoria elegans. Polar Biology, 31: 47-51.

BARTÁK, M., VRÁBlíkovÁ, H. and HÁJEK, J. (2003): Sensitivity of photosystem 2 of antarctic lichens to high irradiance stress: Fluorometric study of fruticose (Usnea antarctica) and foliose (Umbilicaria decussata) species. Photosynthetica, 41: 497-504.

BeLnAP, J. (2006): The potential roles of biological soil crusts in dryland hydrologic cycles. Hydrological Processes, 20: 3159-3178.

CAMPBell, S. E. (1979): Soil stabilization by a prokaryotic desert crust: implications for Precambrian land biota. Origins of Life, 9: 335-348.

Chartres, C. J. (1992): Soil crusting in Australia. In: Sumner, M. E., Stewart, B. A. (eds.): Soil crusting: chemical and physical processes. Lewis, Boca Raton, Fla. pp. 339-365.

DAnIN, A. (1978): Plant species diversity and plant succession in a sandy area in the northern Negev. Flora, 167: 409-422.

ELDRIDGE, D. J. (1993): Cryptogams, vascular plants, and soil hydro- logical relations: some preliminary results from the semiarid woodlands of eastern Australia. Great Basin Naturalist, 53: 48-58.

ELDRIDGE, D. J., GREENE, R. S. B. (1994): Microbiotic soil crusts: a review of their roles in soil and ecological processes in the rangelands of Australia. Australian Journal of Soil Research, 32: 389-415.

HÁJeK, J., BARTÁK, M. and Gloser, J. (2001): Effects of thallus temperature and hydration on photosynthetic parameters of Cetraria islandica from contrasting habitats. Photosynthetica, 39: 427-435. 
HÁJeK, J., VÁczi, P., BARTÁK, M. and JAHNOVÁ, L. (2012): Interspecific differences in cryoresistance of lichen symbiotic algae of genus Trebouxia assessed by cell viability and chlorophyll fluorescence. Cryobiology, 64: 215-222.

HARPER, K. T., MARBLE, J. R. (1988): A role for nonvascular plants in management of arid and semiarid rangelands. In: Tueller, P. T (ed.): Vegetation Science Applications for Rangeland Analysis and Management. Kluwer Academic Press Dordrecht: Amsterdam, pp. 135-169.

HENRI D. CH. (2011): Durham E-Theses: The physiological response of sub-Arctic lichens to their abiotic environment. Thesis (Masters), 127 p. (http://etheses.dur.ac.uk/623/1/All_together_W_corrections.pdf?DDD1+)

JupA, R., HáJeK, J., HAZdrová, J. and BARTÁK, M. (2012): Interspecific differences in photosynthetic efficiency and spectral reflectance in two Umbilicaria species from Svalbard during controlled desiccation. Czech Polar Reports, 2: 31-41.

KAPPEN, L. (1993): Plant activity under snow and ice, with particular reference to lichens. Arctic, 46: 297-302.

Kappen, L., Schroeter, B., Scheidegger, C., Sommerkorn, M. and Hestmark, G. (1996): Cold resistance and metabolic activity of lichens below $0^{\circ} \mathrm{C}$. Advances in Space Research, 18: 119128.

Kappen, L., Sommerkorn, M. and Schroeter, B. (1995): Carbon acquisition and water relations of lichens in polar regions-potentials and limitations. Lichenologist, 27: 531-545.

KARSTEn, U., Holzinger, A. (2012): Effects on photosynthetic activity, and drought-induced ultrastructural changes in the green alga Klebsormidium dissectum (Streptophyta) from a high alpine soil crust. Microbial Ecology, 63: 51-63.

Karsten, U., LÜtz, C. and Holzinger, A. (2010): Ecophysiological performance of the aeroterrestrial green alga Klebsormidium crenulatum (Charophyceae, Streptophyta) isolated from an Alpine soil crust with an emphasis on desiccation stress. Journal of Phycology, 46: 1187-1197.

KitZing, C., PröSChOld, T. and KarSTEn, U. (2014): Growth, photosynthetic performance and sunscreen contents in different populations of the green alga Klebsormidium fluitans (Streptophyta) from Alpine soil crusts. Microbial Ecology, 67: 327-340.

Li, X.-R., WANG, X.-P., LI, T. and Zhang, J.-G. (2002): Microbiotic soil crust and its effect on vegetation and habitat on artificially stabilized desert dunes in Tengger Desert, North China. Biology and Fertility of Soils, 35: 147-154.

Lukeš, M., ProcházkovÁ, L., Shmidt, V., NedbalovÁ, L. and Kaftan, D. (2014): Temperature dependence of photosynthesis and thylakoid lipid composition in the red snow alga Chlamydomonas cf. nivalis (Chlorophyceae). FEMS Microbiology Ecology. Special Issue: Polar and Alpine Microbiology. 89: 303-315.

Pannewitz, S., Green, T. G. A., Maysek, K., Schlensog, M., Seppelt, R., Sancho, L. G., Türk, R. and Schroeter, B. (2005): Photosynthetic responses of three common mosses from continental Antarctica. Antarctic Science, 17: 341-352.

Schulten, J. A. (1985): Soil aggregation by cryptogams of a sand prairie. American Journal of Botany, 72: 1657-1661.

Schlensog, M., Schroeter, B. (2001): A new method for the accurate in situ monitoring of chlorophyll a fluorescence in lichens and bryophytes. The Lichenologist, 33: 443-452.

St. Clair, L. L., JohANSEn, J. R. and RushForTh, S. R. (1993): Lichens of soil crust communities in the intermountain area of the western United States. Great Basin Naturalist, 53: 5-12.

TSOAR, H., MOlLeR, J. T. (1986): The role of vegetation in the formation of linear sand dunes. In: Nickling, W. G. (ed.): Aeolian geo- morphology. Proceedings of the $17^{\text {th }}$ Annual Binghamton geomorphology symposium. Allen and Unwin, Boston, Mass. pp 74-95.

WEST, N. E. (1990): Structure and function of microphytic soil crusts in wildland ecosystem of arid and semi-arid regions. Advances in Ecological Research, 20: 179-223.

Wiencke, C., Clayton, M. N., Gómez, I., Iken, K., Lüder, U. H., Amsler, C. D., Karsten, U., Hanelt, D., Bischof, K. and Dunton, K. (2006): Life strategy, ecophysiology and ecology of seaweeds in polar waters. Reviews in Environmental Science and Bio/Technology, 6: 95-126. 
Wu, L., LaN, S., ZHANG, D. and Hu, C. (2012). Functional reactivation of photosystem II in lichen soil crusts after long-term desiccation. Plant and Soil, 369: 177-186.

Wu, L., Zhang, G., LAN, S., Zhang, D. and Hu, C. (2013): Microstructures and photosynthetic diurnal changes in the different types of lichen soil crusts. European Journal of Soil Biology, 59: 48-53.

YAIR, A. (1990): Runoff generation in a sandy area - the Nizzana sands, western Negev, Israel. Earth Surface Processes Landforms, 15: 597-609. 